\title{
Kerklike Joernalistiek in diens van Aktuele Teologie en Kerklike Praktyk
}

\author{
D J C VAN WYK
}

\section{Uittrede Prof F J van Zyl}

Tydens die fakulteitsopening op 15 Februarie 1978 het prof F J van Zyl die woord gevoer. Dit was aan die begin van sy laaste jaar as hoogleraar in Godsdiens- en Sendingwetenskap aan die Universiteit Pretoria. In sy lesing het hy gepleit vir groter en meer geïntegreerde aktualiteit in ons teologie. Daarmee bedoel hy nie situasie-teologie nie maar 'n teologie wat grondig kennis neem van die situasie waarin hy leef en spreek. Dit, het prof Van Zyl aangetoon, was in die jare wat verby is ' $n$ leemte in ons teologiebeoefening.

Hierdie artikel word saam met ander aan prof Van Zyl opgedra aan die einde van 'n professoraat van 18 jaar. Naas ' $n$ huldiging van die voortreflike werk van hierdie 18 jaar wil dit voortgaande aandag vra vir dié oproep tot 'n meer aktuele teologie.

Dit was altyd oorheersende indrukke wat prof Van Zyl se teologiese werk gelaat het: Hegte Skrifgebondenheid; 'n eie diep belewenis van en aangegryp wees deur die waarheid van die Woord; weiering dat die spook van situasie- of aktualiteitsteologie hom daarvan weerhou om sy teologie aktueel te beoefen.

Hierdie spook is immers een van die hoofredes dat daar gekla moet word oor die gebrek aan die aktuele in ons Hervormde teologiese arbeid. Daar is 'n simptoom van sterielheid, stagnasie wat verontrustend is. Daar is ' $n$ gemis aan betrokkenheid by die worsteling van vandag. Dit is 'n handige tegniek om verskynsels wat 'n appèl makk op jou onaktiwiteit altyd af te maak as ou, negentiende eeuse dwalings.

Daar is meer redes waarom die Hervormde bydrae tot ' $n$ selfstandige Suid-Afrikaanse teologie onbevredigend en skraal is en waarom min werke van formaat en invloed verskyn het: Onderlinge stryd binne die teologiese fakulteit voor-, tydens- en na die Geysersaak in die sestiger jare, onredelike eise aan teologiese professore se betrokkenheid aan prakties-kerklike, administratiewe werk; eensydige besig-wees met die problematiek rondom die rassekwessie; daaruit voortvloeiend groot aandag vir die historiese en verheerliking van alle vorme van konserwatisme. Hierdie faktore moet uitwerking hê op die teologie: 'n Bang, geslote, afwerende, bewarende, na binne gekeerde houding wat min wat nog werklik ondernemend en ekspe- 
rimenteel is in die teologie laat oorbly. Nuwe indringende denke oor aktuele sake word ervaar as ' $n$ gevaarlike en verwarrende gestoot en getorring aan beproefde standpunte van die kerk. Kritiese toetsing aan die Skrif van aanvaarde standpunte van die kerk en openhartige meningswisseling daaroor in kerklike tydskrifte word beveg as verwarrend en ' $n$ bedreiging van geloof en kerk. In hierdie situasie raak die apostolaatsdimensie in die teologie almeer soek. Daar is besluite en skryfwerk uit die verlede wat werklik nie diepte weerspieël nie. Dat onder baie van hierdie genoemde tendense 'n lelike onreformatoriese houding skuil, word nie opgemerk nie. 'n Eienaardige houding van teologiese meerderwaardigheid vind min regverdiging in 'n kragtige kerklike lewe, teologiese wetenskapsbeoefening en 'n hoorbare stem in die wêreld.

Hierdie eerlike poging tot diagnose, aanvullend by wat prof Van Zyl gestel het, mag seer maak. Dit mag egter nie daarom vermy word nie. Wat seer maak, is dikwels genesend en maak sterk.

\section{Diskrepansie tussen Teoloog en Lidmaat}

Intussen het prof G M M Pelser op 12 Mei 1978 op versoek 'n lesing voor die Pretoriase predikante gehou oor die vraag of daar 'n diskrepansie bestaan tussen teoloog en lidmaat. Hy kom tot die slotsom dat daar wel 'n diskrepansie bestaan; enersyds 'n geregverdigde, want dit behoort so te wees dat die teologiese fakulteit die kerk altyd 'n ent vooruit is. Aan die anderkant is dit egter ook so dat die Hervormde teoloog sy vak moet beoefen binne die Reformatoriese tradisie. Die Reformasie het die deur wyd oopgemaak vir krities-wetenskaplike Bybelondersoek. Is die nodige uitlaatklep egter vir die teoloog gelaat om sy bevindinge bekend te maak? Indien nie, kan voortgegaan word om van die teoloog streng wetenskaplike studie te vereis? Is die teoloog, van wie verwag word om binne die grense van die belydenis en die heersende Bybelbeskouing te bly, nog vry om die resultate van sy studeerkamerondersoek aan die lidmate bekend te maak?

In sy poging tot die vasstelling van die oorsake vir genoemde diskrepansie, stel prof Pelser ' $n$ verdere reeks vrae van belang: Is lidmate voldoende op hoogte met kerklike standpunte? Stem lidmate in met kerklike standpunte? Is die kerk voldoende bewus van die vraagstukke wat by lidmate leef? Fouteer die kerk nie om ou oplossings aan te bied vir hedendaagse probleme nie? Bestaan daar nie ' $n$ ontsaglike kloof tussen die werklikheid waarin lidmate leef en kerklike standpunte nie? Is die kerk nie dikwels ver agter sy lidmate as gevolg van verkeerde vertrekpunte nie? Is daar diskrepansie tussen die lewensvoering van die predikant en die lidmaat ten opsigte van byvoorbeeld deelname aan politiek? 
Dit spreek vanself dat in die beantwoording van hierdie vrae en in die soektog na 'n oplossing van hierdie probleem die taak van 'n doeltreffende kerklike joernalistiek sterk in die gesigsveld kom. So het prof Pelser dit ook gedoen.

\section{Die opdrag aan die Kerklike Joernalistiek}

Oor die taak, doel en metode van 'n kerklike joernalistiek is in die Nederduitsch Hervormde Kerk en ook wyer nog min besin en niks geskryf nie. Vandaar die geskarrel oor 'n eenvoudige vraag: Mag die amptelike orgaan van die kerk soos Die Hervormer naas amptelike standpuntstelling dan nie ook openhartige diskussie en kritiese bevraagtekening van kerkstandpunte weerspieël nie? Met ander woorde moet die amptelike kerktydskrif net altyd sê: So het die kerk besluit. Mag dit nie ook sê: So behoort die kerk te besluit nie? Voorlopig en versigtig kan die opdrag en inhoud van 'n kerklike joernalistiek onder twee hoofpunte saamgevat word.

\section{(a) Opbouing in die geloof}

Geloof en lewe in kerk en teologie het altyd 'n opbouende, bewarende aspek en karakter. Die taak van die kerklike tydskrif hierin kan verder onderskei word in

\section{(i) Amptelike standpuntstelling}

Prof Pelser het in genoemde lesing besorgdheid uitgespreek oor die vraag of lidmate voldoende op hoogte is met amptelike standpunte van die kerk. Daar is rede vir die besorgdheid. Daar is natuurlik vir die kerk verskillende kanale waarlangs hy standpunte en besluite (aan sy lidmate) kan bekendstel. Die kerklike tydskrif, veral nog as dit amptelike orgaan van die kerk is, is daarin 'n voor-die-handliggende medium. Die kerkvolk het voorligting nodig oor wat in kerken meerdere vergaderings beslis word. Hulle moet geïnformeer word: So sê die kerk, so het die kerk besluit. Dit is absoluut noodsaaklik vir die toerusting van die lidmaat van die kerk dat hy daaroor helderheid en sekerheid sal hê. Onkunde daaroor is ' $n$ besliste rede vir 'n kloof tussen sy lewe en die kerk se teologiebeoefening. In 'n blad soos Die Hervormer kan en behoort selfs nog meer as in die verlede weerspieëling van kerkbesluite te wees.

\section{(ii) Beriggewing}

Dit is die taak van die Kerklike Joernalistiek om uitgebreide, objektiewe feitlike en grondige informasie aan sy lesers te bied; in die eerste plek fotografering en beriggewing van alle gebeure wat vir die 
kerk van belang is. Verder, om aan die lesers ' $n$ helder beeld te gee van wat op teologiese vlak en in die kerklike praktyk gebeur. Nuwe ontwikkelinge in kerk, teologie en maatskappy moet aangetoon word. Vir sy eie lewe en oordeel is dit vir die lidmaat van die kerk noodsaaklik om 'n goeie deursnee-weergawe te kry van wat in die kerk, en dan nie net die eie kerk nie maar die kerk oor die wêreld leef aan gedagtes en ontwikkelinge: Rapportering en kommentaar in woord en beeld.

In hierdie proses moet die kerklike joernalistiek dus 'n weerspieëling wees na die kerkvolk toe van wat op teologiese vlak gaande is. Dit moet egter nie net feitlik aangebied word nie maar vertaal word, omskryf word, sodat dit binne die bevattingsvermoë van die kerkvolk kan kom. Die teologiese arbeid en denke moet vir die kerkvolk bevatlik gemaak word. So dien die kerklike tydskrif as uitlaatklep na die kerkvolk toe van wat op wetenskaplik-teologiese vlak beoefen word. So help die kerklike joernalistiek om alle teologiese arbeid by sy werklike adres te bring: Die gemeente in sy feitlike situasie.

Langs hierdie weg kan die groter wordende tweespalt tussen kerklike prediking en wetenskaplike bestudering van die Skrif ook bekamp word. Kansel en kateder moet nie saamval nie, maar moet op 'n vrugbare wyse op mekaar betrokke bly. Die hedendaagse Bybelwetenskap het te vervreem geraak van 'n baie belangrike adres: Die Christelike gemeente. ${ }^{1}$

In vergelyking met die sekulêre pers het die kerklike pers, sover dit beriggewing aangaan, 'n groot agterstand. Die kerk beskik eenvoudig nie oor die uitgebreide masjinerie om van dag tot dag, oomblik tot oomblik, sy hand op die pols van alle nuuswaardighede te hê nie. Dit is trouens ook nie nodig nie omdat die nuus wat die kerklike tydskrif aanbied in karakter totaal verskil van dié waarin die sekulêre pers geïnteresseer is.

\section{(iii) Meningswisseling en standpuntstelling}

Die vraag ontstaan: Is polemiek in die kerklike tydskrif nodig en gewens? Moet daar ook gesê word, benewens wat die kerk besluit het, wat die kerk behoort te besluit? Moet die kerkblad se beriggewing naas sy feitlike, ook 'n vormende aspek hê?

Hierop moet onomwonde ja geantwoord word. Vir gesonde perspektief is ontleding en toetsing nodig, ook van die kerk se standpunte. Daarsonder het die Protestantisme onder ons gesterf. Kerklike besluite moet raakgevat, geïnterpreteer en aan die enigste norm van die Kerk en Teologie, die Skrif getoets word. Dat die bedenklike magsposisie en magsmisbruik wat die sekulêre joernalistiek hiermee verwerf het vir baie 'n renons gegee het, mag die kerklike joernalistiek nie van hierdie lewensbelangrike funksie beroof nie. Dit spreek vanself dat die kerklike joernalistiek hom deeglik moet vergewis dat 
hy in die proses van diskussie en meningswisseling die geloof bou en die kerk dien en dit nie afbreek nie.

In die kerklike joernalistiek moet die teologiese fakulteit geprikkel word, gekonfronteer word met wat op die kerklike akker gepraat en gevra word, dit vir die teologie vertolk. Netsoos die kerkvolk gedien word met wat op teologiese vlak beoefen word; gesprekvoering dus in twee rigtings.

Alle uitsprake en standpunte van die kerk moet getoets word aan die enigste norm waaruit die kerk leef en wat hy ken: Die openbaring in Jesus Christus. Dat in die proses van toetsing, langs die weg van diskussievoering en gesprek verskil van insig oor kerklike besluite en nuwe ontwikkelinge kan ontstaan, hoef nie tot verwydering te lei nie. Meningsverskille kan oorbrug word sonder om in onwaaragtige kompromie te verval.

Die kerklike tydskrif moet op vrae, sowel in kerk as in maatskappy ingaan, kommentaar lewer, dissiplinerend vir denke en koers, informasie en oriëntasie gee. Dit moet ' $n$ kritiese evaluasie gee van alle teologiese en kerklike aangeleenthede in hulle relasie tot geloof en lewe. Sy taak is kritiese begeleiding oor gebeure en probleme, vanuit die evangelie, sonder om hom met strominge of opvattinge te vereenselwig. Binne die Reformatoriese belydenis is daar immers ruimte vir verskeidenheid. ${ }^{2}$

Langs hierdie weg kan die kerklike pers nooit ' $n$ bedenklike magsposisie verkry of druk in ' $n$ bepaalde rigting uitoefen deur middel van eensydige standpuntinname nie. Nuwe sake kan krities begelei word want daar is 'n normatiewe uitgangspunt. Van daaruit is kerklike joernalistiek meningsvormend. Vanuit die normatiewe uitgangspunt moet vereenselwiging met groepe vermy word, moet die kerkblad in diens bly van die hele kerk, moet mense leer om na mekaar te luister deurdat hulle geleer het om na die Woord te luister.

Dit mag nooit kleurloosheid beteken nie. Geen joernalis is ooit neutraal nie. Ook die kerklike joernalis nie. Hy sien die dinge vanuit ' $n$ bepaalde visie. Hy is altyd besig om te interpreteer. Hy spreek daarin nooit ' $n$ laaste woord nie. Ook sy woorde moet altyd krities gelees word. Maar hy moet toets en interpreteer en ontleed, om aan sy lesers 'n skerper visie op die werklikheid te gee. Daarvoor moet hy self skerp insig hê op wat in die kerke aangaan. ${ }^{3}$

Indien die kerklike joernalistiek hierdie funksies doeltreffend kan verrig, sal dit nie net die teologiese beoefening stimuleer nie maar ook die kerklike praktyk en opbouing in geloof van die lidmate van die kerk dien. Dit sal groter vrymoedigheid kweek om oor Bybel, kerk en geloof te dink, te skryf en te praat. Waar Christene onderskeidingsvermoë aangeleer het, verval hulle nie meer so maklik in diens van ekstreme rigtings nie. ${ }^{4}$ Die oomblikke van diskussie op 
soek na die waarheid tussen gelowiges, verteenwoordig nie van die swak oomblikke in die lewe van die kerk nie.

Dat die taak van die kerklike pers wyer gaan as net amptelike standpuntstelling, was nog altyd aanvaar. In die geval van Die Hervormer is dit so van sy ontstaan af. Daarom kon die Kommissie van die Algemene Kerkvergadering homself ook soos volg uitlaat in 'n verklaring van 1975: "Gebruikmaking van die kerklike pers deur lidmate en ampsdraers om menings te wissel en deur onderlinge ope gesprek tot liefde en goeie werke aan te spoor, is vir die kerk nuttig en hierby hoef omstrede sake nie uit te bly nie."5 'n Kerklike tydskrif wat maar net weekliks of maandeliks as nuusbrief verskyn, of maar net die kerk se standpunte weerspieël, is niks werd nie. Die kerklike joernalistiek moet die kerk help om relevant te wees tot die situasie waarin hy leef en spreek.

\section{(b) In diens van die apostolaat}

Die kerklike pers rig hom egter nie net na binne, en beywer hom nie net vir die informering en opbouing in geloof van die gelowiges nie. Die kerklike pers het ook ' $n$ taak in diens van die apostolaat van die kerk. Hieroor was ook in die verlede weinig werklike besinning. Wat doen die kerk in sy joernalistiek om met die buitekerklike, die mens wat die taal van die kerk nie meer ken en verstaan nie, te praat? Daar word baie oor die buitekerklike geskryf, maar min vir hom, min gesprek met hom gevoer, dat hy kan hoor en verstaan.

Voorheen is gesê dat die kerklike pers op geen wyse spreekbuis vir groepe of modaliteite in die kerk moet wees nie. Dit moet spreekbuis vir die evangelie van Jesus Christus in die wêreld wees! Dit mag nie druk en propaganda in belang van 'n groep uitoefen nie. Dit moet druk uitoefen in naam van en uit krag van die evangelie van Christus in die wêreld. Veral die Dogmatiek en Godsdiensfilosofie het, soos deur prof Van Zyl in genoemde lesing aangedui, in die aktuele teologiebeoefening 'n geweldige taak. Die kerklike pers moet die egte, oorspronklike Christelike apologia vir die kerk opnuut gaan ontdek en bruikbaar maak; die kerk se verantwoording oor wat hy glo en hoop in en aan die wêreld verwoord. (I Petrus 3:15); nie propagandisties nie, maar appèllerend. Daarom sal veel meer as net kerklike onderwerpe in die kerklike tydskrif ruimte vind: Ook die politiek, die oorlog, die kultuur. Oor kontroversiële sake moet informasie gegee en geïnterpreteer word.

\section{Die Metode van die Kerklike Joernalistiek}

Die sekulêre joernalistiek bied 'n magdom tegnieke wat die kerk nog nie leer gebruik het nie. Waarom kan hierdie tegnieke nie gekersten 
en in diens van die evangelie geneem word nie? Hier word volstaan met enkele opmerkings. ${ }^{6}$

(a) Skrywers moet leer om die kerngedagte van wat hy wil sê, voorop te stel. Baie artikels in ons kerklike tydskrifte is soos preke. Dit begin so ver weg van die werklike punt waarom dit gaan, dat as die leser die lang omweg van weeg, aanvaar, verwerp, deurloop het, hy nie meer kan onthou waarom dit gaan nie. Dit is veel meer boeiend om onmiddellik die kern van jou stelling of saak raak te vat, en dan die nodige argumente daar rondom op te bou.

(b) Behandel en beklemtoon in een artikel hoogstens twee of drie kernsake. Moenie 'n wye, uitgestrekte veld probeer dek nie.

(c) Skryf kort en pakkend. Ons is in die kerk te geneig om die kwaliteit van 'n artikel net soos met preke, te meet aan sy lengte. Lang artikels word nie gelees nie of word eenkant neergesit om te wag vir'n dag waarop daar tyd is - iets wat selde in ons dae gebeur.

(d) Iemand wat in 'n kerklike tydskrif lees, wil weet wat sê die Bybel, die kerk of die skrywer van die artikel oor'n saak. Gewoonlik is lesers nie geïnteresseerd in wat 'n skrywer oor 'n klomp ander skrywers dink of sê nie. Die gewoonte om eindelose rye Bybeltekste aan te haal ter stawing van ' $n$ stelling is in 'n kerkblad vermoeiend vir die leser en totaal onnodig. Effektief is dit ook nie. Die kerkvolk word nie geboei deur 'n vergelykende skryfmetode nie maar deur 'n skryfstyl wat bondig, tersake en op die man af tot hom spreek.

(e) Gebruik natuurlike taal. Soos in preke is die skryfstyl in kerkblaaie dikwels gekenmerk deur onnatuurlikheid, teologiese hoogmoed en bombasme. Argaïsmes en domineestaal is iets anders as Bybelse taal en - woordgebruik.

(f) 'n Skrywer behoort homself altyd af te vra: Vir wie skryf ek en wat wil ek vir hulle sê? Dit is 'n elementêre vraag, maar wat min skrywers hulself blykbaar ooit afvra. Om dit wel te doen, dra baie daartoe by dat 'n skrywer positief en konstruktief skryf.

Naas hierdie enkele oorwegings moet gestel word dat daar teenoor enkele ander metodes en intensies van die sekulêre koerantwese pertinent nee gesê moet word deur die kerklike joernalistiek.

(a) Die eerste is dat die kerklike pers nooit sensasioneel en oopvlekkend van aard moet skryf nie. Dit moet altyd opbouend, stimulerend, verrykend vir kennis van geloofs- en kerklike lewe wees. Om te reformeer, is om op te bou, nie om af te breek nie. Onder die indruk dat in die kerk en samelewing die sondes net altyd toegesmeer word, stel die koerantwese hom graag self aan as die groot oopvlekker en verklikker. Dit gaan met harteloosheid en liefdeloosheid gepaard wat die kerk nooit kan aanvaar nie. In die onlangse gebeure rondom die Rhoodie broers van die Departement van Inligting, het sekere koerante self later geskrik vir die onnodige leed wat die mense 
aangedoen is - 'n proses wat deur die pers as "verklikker" aan die gang gesit is.

Die kerk kan nie anders as om hom fel te verset teen alle verslaggewing met die tong in die kies nie; 'n tegniek van intimidasie deur kansellasie. Alles wat verborge is, sal aan die lig kom. God sal dit aan die lig bring. Maar ons is nie God nie. Die sonde moet aan die lig kom. Maar dan soos Christus met mense gehandel het: Mild en verdraagsaam. ${ }^{7}$ In die kerklike joernalistiek word nie geskel en bitsighede kwytgeraak nie. Daar word mense gedring deur die liefde van Christus.

(b) Die sekulêre joernalistiek pretendeer graag dat hy sonder vooroordeel aan alle rigtings 'n platform wil bied. "As gespreksmedium is hy - kragtens sy funksie - ingewerp in die kaleidoskoop van verskillende aksente en standpuntstellings. In sy nuuskolomme praat eksistensialiste, moraliste, nihiliste - hetsy deur onderhoud van 'n nuuspersoonlikheid, hetsy deur openbare verklarings, hetsy deur amptelike standpuntstellings. Die goeie, betroubare koerant het kragtens sy funksie nie sensuur oor menings van mense wat in die stroom van die nuus staan nie. Dis 'n risiko - om die hele wêreld en sy standpuntstellers op jou preekstoel te laat klim. As 'n koerant dit weier, is hy nie meer koerant nie. Dan is hy seksionele lyfblad of orgaan. Maar as hy koerant wil wees, is hy 'n forum."8 Aldus dr Willem de Kerk, redakteur van Die Transvaler.

Prof G J Pienaar erken dat die koerante hierin nie altyd billik optree nie. ${ }^{9}$ Word albei kante van elke saak toegelig? Of word dit maar net altyd uit ' $n$ besondere hoek aangebied? Daaroor, sê Pienaar, kan gekla word!

En dr Willem de Klerk laat self in genoemde artikel die kat uit die mou: "Ons Afrikaanse koerante probeer - tot irritasie van sommige deurbreek na die politieke eise van ons tyd en na noodsaaklike en gefundeerde verandering in ons volkeverhoudingsvraagstuk. Ons ervaar te veel in kerklike kringe 'n politieke verkramptheid en wensdinkery wat ons werk probeer aftakel op politieke vlak. Dit bring van die koerant se kant 'n soort "afkoeling"' en onttrekking van 'n kerk en sy vergaderinge wat remmers en stremmers is op die vlak van politieke reoriëntasie." 10

Met ander woorde, solank die kerk die koerante in hul politieke ideale napraat, bied die koerant graag aan die kerk 'n platform. Weier die kerk egter om dit te doen, koel die pers teen die kerk af en "onttrek" hom aan so 'n kerk.

Die kerklike joernalistiek het egter die illusie van objektiwiteit ontgroei. Die kerk werk en leef in al sy uitinge binne vaste grense: Woord en belydenis; en dink vanuit 'n vaste norm en vooronderstelling: Die openbaring in Jesus Christus. Dit bring vir die kerklike pers finale, onontwykbare verantwoordelikheid mee: Die eer van 
God en die heil van die mense. Daarom kan hy nie lustig-waaghalsig, eksperimenteel te werk gaan ter wille van sirkulasie of welke motief ookal nie. Terselfdertyd weet hy onwrikbaar dat die kerk en die evangelie in wie se diens hy staan nie aan Paulus of Cefas of Apollos behoort nie, maar aan Christus.

\section{Slotopmerking}

Die Woord van God is alleen volmaak. Geen woord van 'n mens is dit nie. So is dit ook met die voorafgaande opmerkings oor die kerklike joernalistiek. Dit is 'n poging tot voorlopige besinning oor 'n magtige instrument wat die kerk in sy hande het, swaar gelaai met probleme, en waaroor, soos dit wil voorkom, nog selde werklik ernstig en diepgaande besin is. Dit sal vir die kerk die moeite werd wees om grondige navorsing te doen oor hoe hierdie medium op die heel beste wyse benut kan word.

Benewens bogenoemde, bly daar'n groot klomp kwelvrae oor wat besinning verg. Ons noem enkeles: Finansiële aspekte van die kerklike joernalistiek; die werk en verantwoordelikheid van die redaksie; die draagkrag en betekenis van 'n artikel, brief, hoofartikel; is dit waar dat kerklike tydskrifte swak gelees word; indien wel, waarom; sal dit nie verander as die kerklike lyfblad homself adverteer en verkoop nie; hoe kan die kerkvolk opgevoed word om meer belangstelling te toon in breër kerklike sake en groot wêreldprobleme?

1. C J den Heyer, De Bijbel onder het ontleedmes, Heroormd Nederland, 1 April 1978, bl 5 .

2. K Runia, 1953-1978 en verder, Centraal Weekblad, jubileumnommer, 25 Februarie 1978 , bl 5.

3. W F de Gaay Fortman, Wat bedoelde Diemer?, Centraal Weekblad, jubileumnommer, 25 Februarie 1978, bl 3.

4. Y A Bebié, Die Kirchliche Presse - van "aussen" gesehen, Reformatio, volume 23, Januarie 1974, bl 13-23.

5. Verklaring, Kommissie van die Algemene Kerkvergadering, Die Hervormer, September 1975, bl 20.

6. H T Kerr, How to write an article. Theology Today, volume 31 no 4, January 1975, bl 289-291.

7. Sherwood E Wirt, a New note in Christian Journalism, Christianity Taday, volume 16, February 1972, bl 8-10.

8. W J de Klerk, Kerk en pers, In die Skriflig, September 1975, bl 12-17.

9. G J Pienaar, Boosheid van/in koerante, Die Kerkblad, 12 Mei 1976, bl 8.

10. W J de Klerk, aw, bl 12-17. 